\title{
Blood transfusion requirements after liver biopsy
}

\author{
Brian D O'Brien MD MSc FRCPC
}

BD O'Brien. Blood transfusion requirements after liver biopsy. Can J Gastroenterol 2000;14(10):901-902. It is common practice to type and screen the blood before performing a percutaneous liver biopsy. Many practitioners think that this is unnecessary but do not have a reason to change their practice. The requirements for transfusion after biopsy were determined in a consecutive sample of cases at a tertiary care teaching hospital with the use of health record review and the anecdotal recall of gastroenterologists and others performing biopsies. One of 266 liver biopsies required a transfusion after biopsy over a two-year period. One other case of hemorrhage with a fatal outcome was recalled by several individuals. It is concluded that the incidence of significant hemorrhage after liver biopsy is low, and that it may not be necessary to type and screen the blood of low risk patients before biopsy.

Key Words: Biopsy; Blood transfusion; Liver biopsy; Percutaneous liver biopsy

\section{Besoins en transfusions sanguines après la greffe de foie}

\begin{abstract}
RÉSUMÉ : Il est courant de procéder au typage et au dépistage sanguins avant d'effectuer une biopsie hépatique percutanée. De nombreux médecins estiment que cela est superflu, mais ils n'ont aucune raison de changer leurs habitudes. Les besoins en transfusions après la biopsie ont été mesurés dans le cadre d'un échantillon de cas consécutifs auprès d'un hôpital universitaire de soins tertiaires à partir de l'examen des dossiers et des faits relatés par les gastro-entérologues et autres médecins effectuant les biopsies. Une biopsie hépatique sur 266 a nécessité une transfusion après la biopsie sur une période de deux ans. Un autre cas d'hémorragie fatale, a été relaté par plusieurs personnes interrogées. On en conclut que l'incidence de l'hémorragie significative après la biopsie hépatique est faible et qu'il serait peut-être superflu de procéder au typage et au dépistage sanguin pour les patients à faible risque avant la biopsie.
\end{abstract}

$\mathrm{T}$ he standard order by most physicians before performing percutaneous liver biopsy is to type and screen blood products to speed up the process of acquiring crossmatched blood if it is required after the biopsy. The perception of many physicians is that these transfusions are rarely required. The present study was undertaken to evaluate the requirement for transfusion after percutaneous liver biopsy and to review the practice of routine typing and screening of blood before percutaneous liver biopsy at the authors' hospital.

\section{PATIENTS AND METHODS}

The hospital record database at the Queen Elizabeth II Health Sciences Centre was searched for all patients who had a liver biopsy in the Medical Day Unit as an outpatient between April 1996 and March 1997 or as an inpatient be- tween April 1996 and March 1998. The hospital abstracting process includes noting whether patients have transfusion of blood products. The charts of all patients who had their liver biopsy during these time periods and had a blood product transfused during the same admission were examined. The records were screened for the following information: the type of biopsy obtained, the pathological findings, the hemoglobin, platelet count, international normalized ratio (INR) and partial thromboplastin time (PTT) before the biopsy, the use of nonsteroidal anti-inflammatory agents, the timing of the blood product transfusion and the relation, if any, between the transfusion and the liver biopsy.

All physicians performing liver biopsies in the gastroenterology, general internal medicine and general surgery divisions were asked to report any cases of a significant hemorrhage after a percutaneous liver biopsy. 


\section{RESULTS}

A review of the health records revealed that 266 biopsies were performed between April 1996 and March 1998. To assess the completeness of this search, the pathology department records were reviewed, and all of these 266 cases and an additional 92 were found to have been performed on an outpatient basis. The 266 included 28 outpatient biopsies performed in the medical day unit; none required admission. Of the 238 inpatient biopsies, 135 had no transfusions during the same hospital admission. Of the 103 patients who had a transfusion during the same admission, 64 received packed red blood cells. The remainder had transfusions of plasma, platelets or albumin. Of the 64 patients who had red blood cell transfusions, 32 had percutaneous liver biopsies, either blind or with the use of ultrasound guidance; all were performed using the Menghini $1 \mathrm{~s}$ technique. Twenty biopsies were done by the transjugular route; seven biopsies were done at the time of surgery or laparoscopy. There was no chart record of the biopsy in five cases. In one case, transfusion was likely related to hemorrhage after the biopsy. In that patient, the INR and PTT were normal but the platelet count was $109 \times 10^{9} / \mathrm{L}$. This 43 -year-old man had previously had a bone marrow transplant, and an inpatient percutaneous biopsy was performed to evaluate significantly elevated liver enzyme concentrations. He developed a pleural effusion after the biopsy, his hemoglobin dropped from 97 to $73 \mathrm{~g} / \mathrm{L}$, and he received a transfusion to restore his hemoglobin to the previous level. Over time, the effusion resolved, and the patient did well in the short term.

The physicians and surgeons who performed liver biopsies could only recall one case in recent years in which a transfusion was required. This patient had a significant coagulation disorder, had a significant hemorrhage after the biopsy and subsequently died.

\section{DISCUSSION}

The charts reviewed suggest that one patient over a two-year period required a blood transfusion after undergoing liver biopsy because of a significant hemorrhage. There is one other anecdotal case within recent memory at this hospital. Both patients had coagulation disorder. The first patient had a platelet count of $109 \times 10^{9} / \mathrm{L}$, significantly below the normal range, and the second patient apparently also had a coagulation disorder. However, of the 103 patients who received a blood transfusion, 15 had a platelet count of less than $110 \times 10^{9} / \mathrm{L}$ and did not have significant hemorrhage. Whether having the patient typed and screened before the procedure sped up the response to the subsequently identified pleural effusion and hemoglobin drop is not clear. Our laboratory can provide crossmatched blood within $4 \mathrm{~h}$ unless there are major difficulties with compatibility.
In 1990, McGill et al (1) from the Mayo Clinic reported 9212 liver biopsies; $0.35 \%$ of patients had significant hemorrhage $-0.11 \%$ of them fatal. They noted that, in patients with malignancy, there is a 10 times greater risk of fatal hemorrhage. Maharaj and Bhoora (2) reported in 1992 that taking more than two passes during a liver biopsy was associated with a higher incidence of hemorrhage. Lindor et al (3) from the Mayo Clinic reported that ultrasonography leads to a lower rate of complications but adds significantly to the expense of the procedure. In a retrospective study of $68,000 \mathrm{bi}$ opsies over 10 years, Piccinino et al (4) noted that death was very infrequent after the biopsy and occurred in nine of 100,000 patients - only in patients with malignant diseases or cirrhosis. They also found that complications were more frequent when biopsy was performed with a cutting needle rather than with an aspiration needle. Sharma et al (5) studied the association between platelet count and the risk of bleeding, and found that platelet counts less than $60 \times 10^{9} / \mathrm{L}$ were associated with more bleeding than counts above $60 \times 10^{9} / \mathrm{L}$.

Results of the present review suggest that blood transfusion is rarely required after percutaneous liver biopsy. Physicians use the transjugular route in patients who have a significant coagulation disorder, ascites or any other factor that might increase the risk of the percutaneous route. In addition, many of the biopsies were performed with ultrasound guidance, which may have reduced the risk of complications. Our data indicate that it is appropriate to continue the practice of typing and screening the blood before percutaneous biopsies in patients in whom there is a coagulation disorder, a reduced platelet count or a likely malignant diagnosis. Otherwise, this procedure is likely not necessary.

ACKNOWLEDGEMENTS: This study could not have been undertaken without the able assistance of Ms Krista Snook of the Health Records Department and my colleagues in the Divisions of Radiology and General Surgery and the Department of Diagnostic Imaging.

\section{REFERENCES}

1. McGill DB, Rakela J, Zinsmeister AR, Ott BJ. A 21-year experience with major hemorrhage after percutaneous liver biopsy. Gastroenterology 1990;99:1396-400.

2. Maharaj B, Bhoora IG. Complications associated with percutaneous needle biopsy of the liver when one, two or three specimens are taken. Postgrad Med J 1992;68:964-7.

3. Lindor KD, Bru C, Jorgensen RA, et al. The role of ultrasonography and automatic-needle biopsy in outpatient percutaneous liver biopsy. Hepatology 1996;23:1079-83.

4. Piccinino F, Sagnelli E, Pasquale G, Giusti G. Complications following percutaneous liver biopsy. A multicentre retrospective study on 68,276 biopsies. J Hepatol 1986;2:165-73.

5. Sharma P, McDonald GB, Banaji M. The risk of bleeding after percutaneous biopsy: relation to platelet count. J Clin Gastroenterology 1982;4:451-3. 


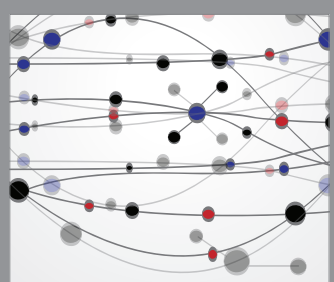

The Scientific World Journal
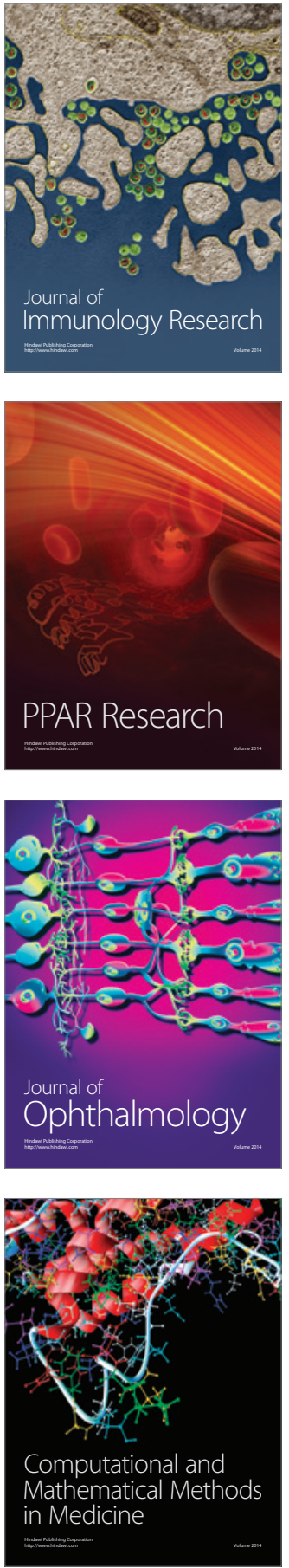

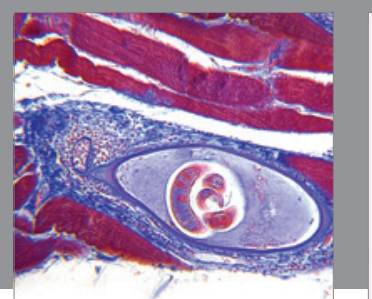

Gastroenterology Research and Practice

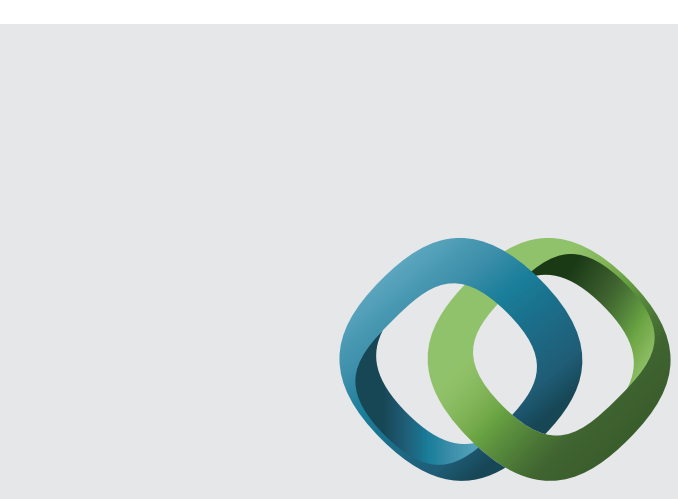

\section{Hindawi}

Submit your manuscripts at

http://www.hindawi.com
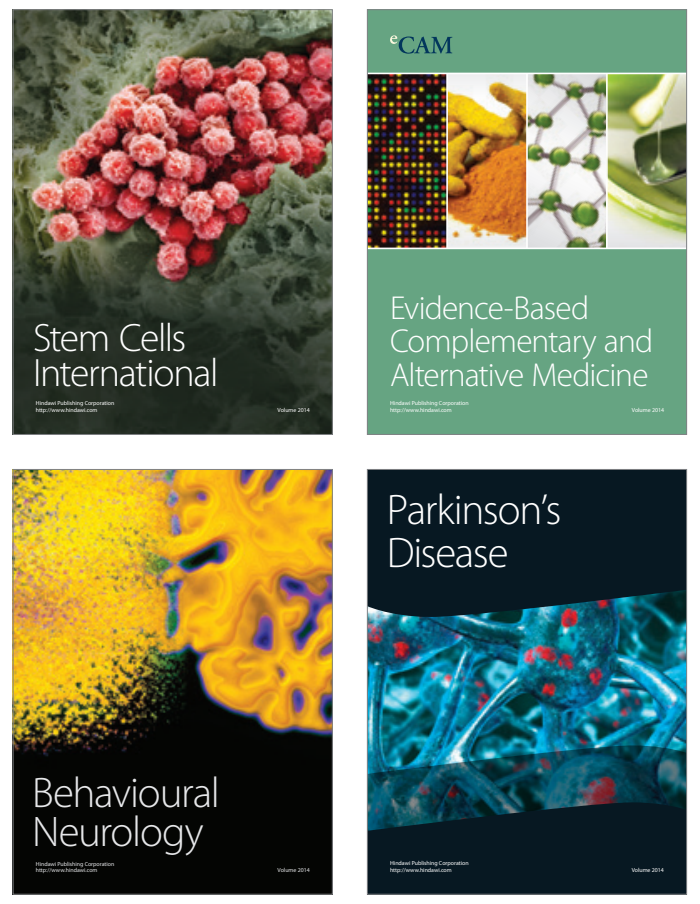
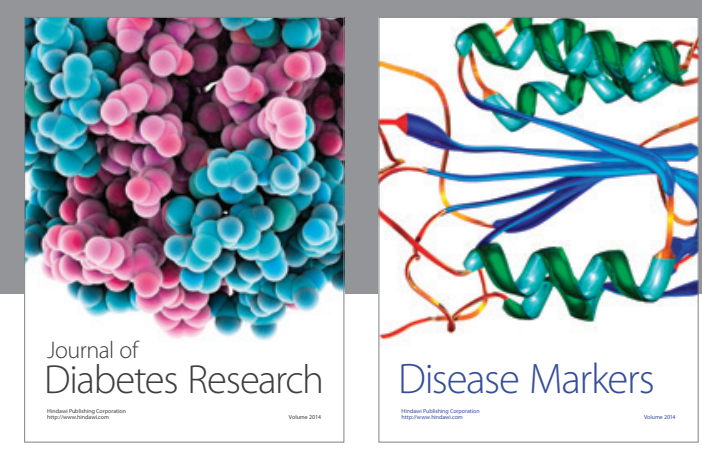

Disease Markers
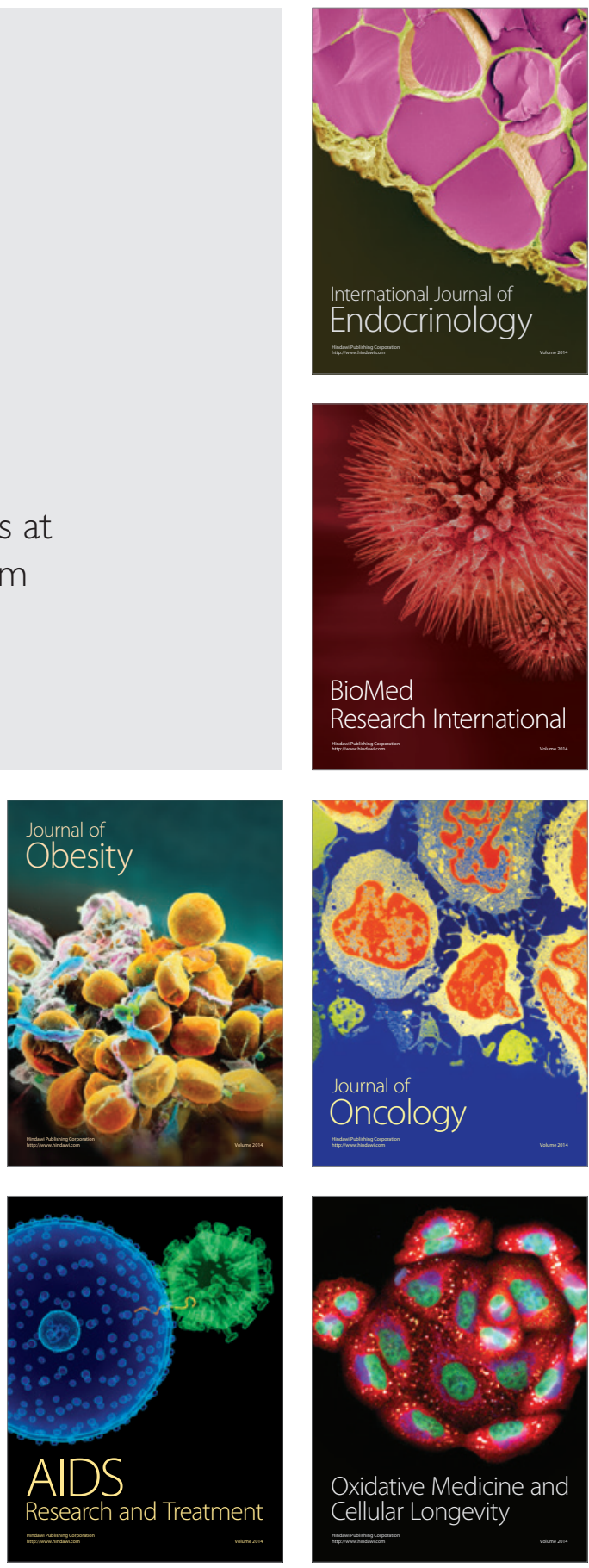